Retorno de investimentos QII $_{\mathrm{N}}^{A}$ comunifação

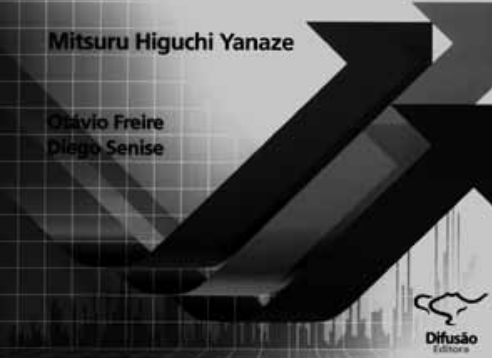

Retorno de investimentos em comunicação: avaliação e mensuração Mitsuru Higuchi Yanaze / Diedo Senise / Otavio Freire São Caetano do Sul, SP:
Difusão Editora, 2010
424 páginas Resenhado por:
Luiz Alberto de Farias 


\title{
Mensurar é mais que preciso
}

\section{Measuring is more \\ than just necessary}

\section{Medir es más}

que necesario

\begin{abstract}
A valiar, mensurar, medir, contabilizar: palavras em princípio distantes do Adia a dia e até pouco tempo ausentes - ou estranhas - no vocabulário de muitos profissionais de comunicação, tornam-se rapidamente verdadeiros mantras para os que desejem manter-se conectados às transformações e às demandas contemporâneas do campo. Por mais que alguns de nós ainda nos debrucemos nos versos popularizados por Amália Rodrigues, já não há espaço para se dizer que a "comunicação não é precisa".

Diversos estudos - tanto no âmbito universitário quanto no mercadológico - têm sido feitos no sentido de buscar métodos, técnicas e instrumentos que permitam dar às ações de comunicação mais tangibilidade - exigida por quem investe, por quem contrata. Ainda que saibamos que imagem e reputação estejam além das planilhas, por mais que compreendamos que estamos na era do relacionamento e que estas, bem construídas, são verdadeiros diferenciais competitivos, precisamos, por outro lado, sem desprezar os estudos qualitativos, enveredar pelo campo do cada dia mais respeitado ROI (return on investment).
\end{abstract}

Ainda que alguns possam ter pensado que isso seria mais uma das muitas modas presentes nas universidades e nos ambientes corporativos, acertaram os que dedicaram tempo e trabalho a compreender as demandas por métricas e fizeram desses processos objeto de estudo ou de trabalho. Afinal, qual comunicador, ao propor um projeto, uma ação, uma campanha, seja o que for, não ouviu do tomador de decisão a clássica pergunta: "qual o valor do investimento, qual será a taxa de retorno e em quanto tempo este virá?" Neste caso, com toda a certeza, o silêncio não é resposta uma resposta válida.

A partir da criação do Centro de Estudos de Avaliação e Mensuração em Comunicação e Marketing (Ceacom), vinculado à Escola de Comunicações e Artes da Universidade de São Paulo (ECA-USP), Mitsuru Higuchi Yanaze, pro- 
fessor titular da instituição, implantou as bases que originaram o livro Retorno de investimentos em comunicação. Além do respeitado e experiente Mitsuru, um grupo de pesquisadores de alto nível compõe o Ceacom, dentre os quais se detacam os talentosos professor Otávio Freire, docente na Esacola de Artes, Ciências e Humanidades de USP (EACH-USP), e Diego Senise, jovem publicitário, ambos coautores da obra aqui resenhada.

Somando-se aos estudos já consolidados por Mitsuru, pode-se dizer que a obra é fruto natural do Ceacom, pois as entrevistas realizadas com cinquenta gestores de comunicação de algumas das maiores empresas brasileiras são parte importante da obra: colocam de maneira clara o que ocorre no mundo corporativo. O livro é dividido em duas partes, das quais a segunda guarda em si a "Pesquisa sobre avaliação dos processos de investimentos em comunicação", desenvolvida pelo Ceacom. Ali se descrevem, além da estrutura e da organização do centro de estudos, o relatório e as principais descobertas oriundas dessa pesquisa.

Na primeira parte são apresentados seis capítulos que permitem ao leitor entender desde a base processos avaliativos e de mensuração. Os textos iniciais dão conta dos conceitos de gestão de marketing e de comunicação integrada, o que permite ao leitor não iniciado compreender os processos de formação da comunicação nos ambientes e nos mercados contemporâneos e aos experts, aprofundar-se nos conceitos claramente trabalhados na obra.

De modo geral, as discussões acerca de finanças e mensuração não são tão comuns em comunicação, o que valoriza os capítulos seguintes, pois tanto o terceiro como o quarto se destinam a discutir esses assuntos - nem sempre claros - a partir de um lugar de fala de comunicadores. Enfim, a linguagem e a sistemática de explicação funcionam para desenvolver a compreensão e sensibilizar o leitor para as metodologias desenvolvidas pelos autores e pelo Ceacom, coordenado por Mitsuru, bem como para introduzir ao quinto capítulo, que se presta a fazer uma cuidadosa revisão da bibliografia sobre ROI em comunicação. O que se destacou é que pouco se escreveu sobre mensuração em comunicação e, por isso, os autores se serviram de obras que trabalharam o tema em outras vertentes, cuja leitura e análise foram feitas com um olhar cuidadoso, reinterpretadas para o campo da comunicação, dando a angulação necessária ao entendimento e à fluidez. Para adaptar modelos, é necessário ser especialista, e é isso o que encontramos nesse trabalho.

O sexto capítulo é destinado a um valioso levantamento das métricas hoje praticadas. São apresentados quinze temas, que dão conta desde o relacionamento com a imprensa até patrocínios, passando por comunicação interna e imagem corporativa, dentre outros. Além da extensa bibliografia antes analisada, esse espaço do livro também é resultado de ampla pesquisa, apresentando métodos de avaliação e de mensuração de diversas corporações nacionais e internacionais. 
Vale lembrar que muitas das metodologias são ilustradas com exemplos práticos, o que instiga o leitor a acompanhar a obra fazendo comparações com o próprio universo, permitindo a aplicação prática em várias situações, dos mais diferentes tipos de organizações. Com mais de quatrocentas páginas, Retorno de investimentos em comunicação merece ser lido com calma e tranquilidade. Trata-se de uma obra que tem tudo para, em lugar da estante, ganhar um lugar bem em cima de nossas mesas de trabalho, permitindo a sua consulta com a frequência das demandas por trabalhos que contemplem em seus objetivos a avaliação e a mensuração de resultados: todo dia, cada dia mais! 